\title{
Underwater Photographic Reconnaissance and Habitat Data Collection in the Florida Keys-A Procedure for Ground Truthing Remotely Sensed Bathymetric Data
}

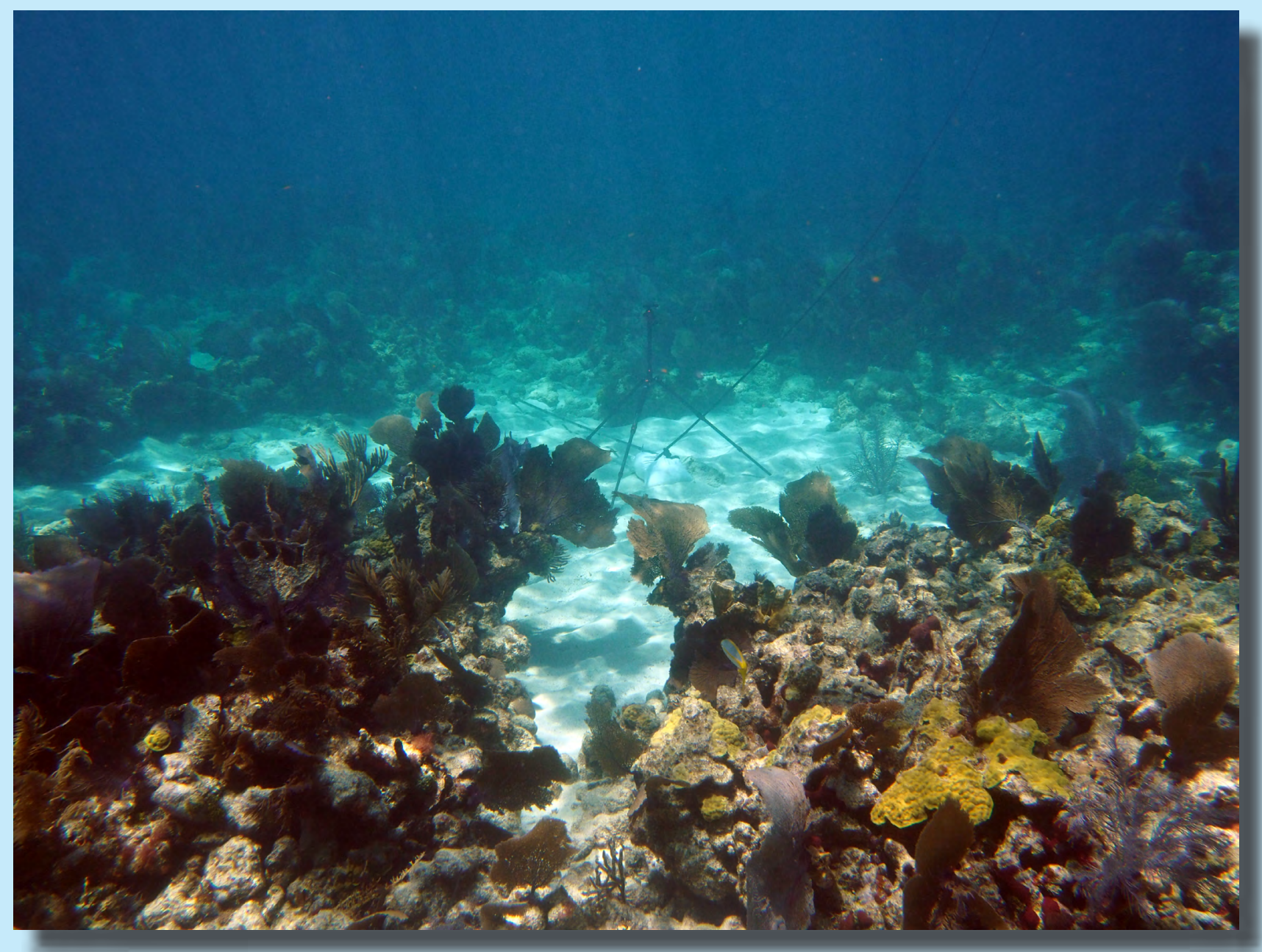

Open-File Report 2020-1118 
Cover. Photographic reconnaissance setup at Turtle Rocks, Florida Keys, Florida. Photograph by Zachery Fehr. 


\section{Underwater Photographic Reconnaissance and Habitat Data Collection in the Florida Keys-A Procedure for Ground Truthing Remotely Sensed Bathymetric Data}

By Zachery W. Fehr and Kimberly K. Yates

Open-File Report 2020-1118 


\title{
U.S. Department of the Interior \\ DAVID BERNHARDT, Secretary
}

\author{
U.S. Geological Survey \\ James F. Reilly II, Director
}

U.S. Geological Survey, Reston, Virginia: 2020

For more information on the USGS - the Federal source for science about the Earth, its natural and living resources, natural hazards, and the environment—visit https://www.usgs.gov or call 1-888-ASK-USGS.

For an overview of USGS information products, including maps, imagery, and publications, visit https://store.usgs.gov/.

Any use of trade, firm, or product names is for descriptive purposes only and does not imply endorsement by the U.S. Government.

Although this information product, for the most part, is in the public domain, it also may contain copyrighted materials as noted in the text. Permission to reproduce copyrighted items must be secured from the copyright owner.

Suggested citation:

Fehr, Z.W., and Yates, K.K., 2020, Underwater photographic reconnaissance and habitat data collection in the Florida Keys - A procedure for ground truthing remotely sensed bathymetric data: U.S. Geological Survey Open-File Report 2020-1118, 13 p., https://doi.org/10.3133/ofr20201118.

ISSN 2331-1258 (online) 


\section{Acknowledgments}

We thank Stephanie Arsenault, Mitch Lemon, and Nathan Smiley of the U.S. Geological Survey for their assistance in developing and refining the procedures outlined in this report. They also provided much-appreciated aid in fieldwork preparation and operations. We also thank Ilsa Kuffner for developing the Recon Dive Habitat Sheet. This work was funded through the 2018 U.S. Geological Survey Hurricane and Wildfire Supplemental Funding. Data were collected under Florida Keys National Marine Sanctuary permit FKNMS-2016-068. 



\section{Contents}

Acknowledgments ……...................................................................................................................

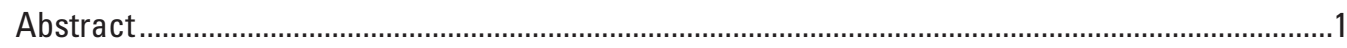

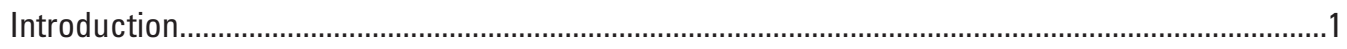

Methods

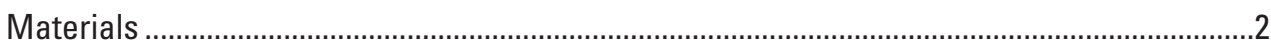

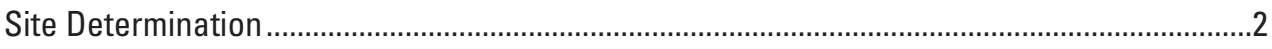

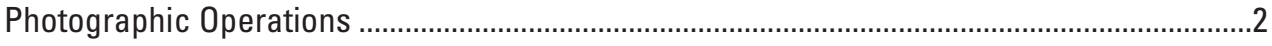

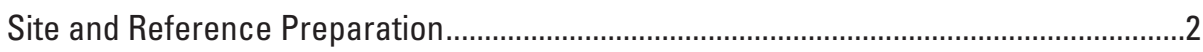

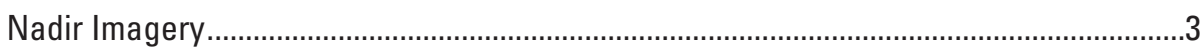

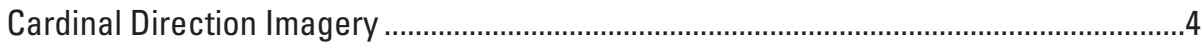

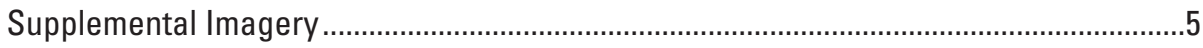

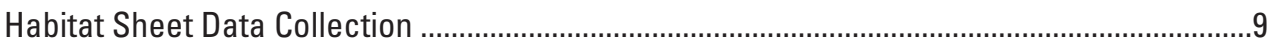

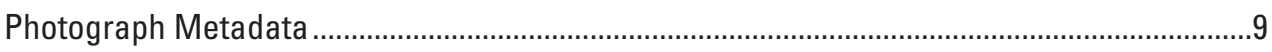

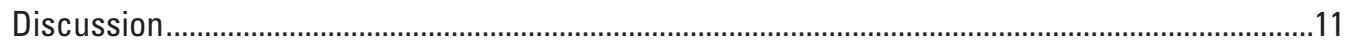

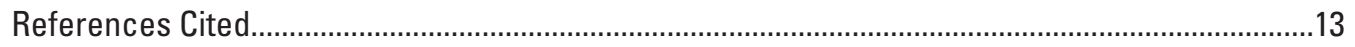

\section{Figures}

1. Map showing the ten "hot spot" sites chosen for Turtle Rocks, Florida Keys, Florida; the location is shown in the inset map

2. Underwater photograph of the dive slate (showing "Turtle Rock site 7") which was used to demarcate the beginning of the series of photographs taken at Turtle Rocks site 7 on the camera's chronologically ordered secure digital

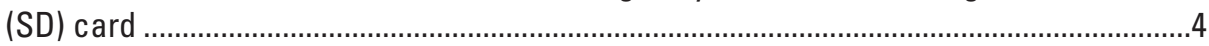

3. Photograph of an example nadir shot at Turtle Rocks site 7 .............................................5

4. Photograph of the tripod and reference rod setup at Turtle Rocks site 7 .......................6

5. Photographs showing cardinal direction viewpoints at Turtle Rocks site $7(A, C$, $E, G)$ with the reference dive slate and $(B, D, F, H)$ without the reference dive slate.......7

6. Photograph (a macro shot) of seafloor sediment alongside a reference ruler at

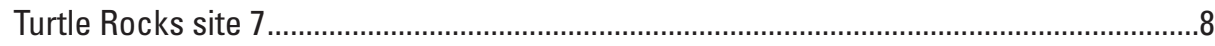

7. Photograph showing sediment accretion around a gorgonian coral species found at Crocker Reef site $3(A)$ before sediment removal from the holdfast and $(B)$ after sediment removal from the holdfast.

8. Digital image of the completed "Ecosystem Processes Impacting Coastal Change (EPIC) Recon Dive Habitat Sheet" for Turtle Rocks site 7.

\section{Table}

1. List of fields associated with image P3311661.JPG (fig. 5A) in the photograph metadata 


\section{Conversion Factors}

U.S. customary units to International System of Units

\begin{tabular}{lcl}
\hline \multicolumn{1}{c}{ Multiply } & By & \multicolumn{1}{c}{ To obtain } \\
\hline & Length & \\
\hline inch (in.) & 2.54 & centimeter $(\mathrm{cm})$ \\
inch (in.) & 25.4 & millimeter $(\mathrm{mm})$ \\
foot (ft) & 0.3048 & meter $(\mathrm{m})$ \\
mile (mi) & 1.609 & kilometer $(\mathrm{km})$ \\
mile, nautical (nmi) & 1.852 & kilometer $(\mathrm{km})$ \\
yard (yd) & 0.9144 & meter $(\mathrm{m})$ \\
\hline
\end{tabular}

International System of Units to U.S. customary units

\begin{tabular}{lll}
\hline \multicolumn{1}{c}{ Multiply } & \multicolumn{1}{c}{ By } & \multicolumn{1}{c}{ To obtain } \\
\hline & Length & \\
\hline centimeter $(\mathrm{cm})$ & 0.3937 & inch (in.) \\
millimeter $(\mathrm{mm})$ & 0.03937 & inch (in.) \\
meter $(\mathrm{m})$ & 3.281 & foot (ft) \\
kilometer $(\mathrm{km})$ & 0.6214 & mile (mi) \\
kilometer $(\mathrm{km})$ & 0.5400 & mile, nautical (nmi) \\
meter $(\mathrm{m})$ & 1.094 & yard (yd) \\
\hline
\end{tabular}

\section{Datum}

Horizontal coordinate information is referenced to the North American Datum of 1983 (NAD83). 


\section{Abbreviations}

$\begin{array}{ll}\text { cm } & \text { centimeter } \\ \text { DEM } & \text { digital elevation model } \\ \text { E } & \text { east } \\ \text { EST } & \text { Eastern Standard Time } \\ \text { EXIF } & \text { exchangeable image file format } \\ \text { FAN } & \text { field activity number } \\ \text { GPS } & \text { Global Positioning System } \\ \text { ID } & \text { identification } \\ \text { JPG } & \text { Joint Photographic Experts Group } \\ \text { lidar } & \text { light detection and ranging } \\ \text { m } & \text { meter } \\ \text { N } & \text { north } \\ \text { n/a } & \text { not applicable } \\ \text { NAD83 } & \text { North American Datum of 1983 } \\ \text { ORF } & \text { Olympus Raw Format } \\ \text { S } & \text { south } \\ \text { SAV } & \text { submerged aquatic vegetation } \\ \text { SD } & \text { secure digital } \\ \text { SOP } & \text { standard operating procedure } \\ \text { sRGB } & \text { standard Red Green Blue } \\ \text { USGS } & \text { U.S. Geological Survey } \\ \text { W } & \text { west } \\ \text { \% } & \text { percent } \\ & \end{array}$





\title{
Underwater Photographic Reconnaissance and Habitat Data Collection in the Florida Keys-A Procedure for Ground Truthing Remotely Sensed Bathymetric Data
}

\author{
By Zachery W. Fehr'1 and Kimberly K. Yates²
}

\section{Abstract}

Bathymetric geoprocessing analyses of the Florida Reef Tract have provided insights into trends of seafloor accretion and seafloor erosion over time and following major storm events. However, bathymetric surveys sometimes capture manmade structures and vegetation, which do not represent the desired bare-earth data. Therefore, ground truthing is essential to maintain the most accurate bathymetric data possible. Field procedures were developed in the Florida Reef Tract in order to quickly and accurately collect consistent imagery and habitat data across variable sites. Areas of significant elevation change were determined through elevation change analyses; these areas were targeted for ground truthing in order to check the reliability of the surveys. This report outlines the standard operating procedures for underwater photographic imagery and habitat data collection, as well as procedures for the storage of these photographs and associated metadata. These standard operating procedures ensure the reproducibility of photographic operations and habitat data collection in future field excursions, enable longitudinal visual comparisons alongside seafloor elevation change analyses, and also have the potential to be applied to similar studies in different coastal environments.

\section{Introduction}

Coral reefs provide an integral service for marine organisms and are important for shoreline protection. In addition to serving as a nursery and providing shelter and habitat for diverse marine species, coral reefs and shallow non-coral-dominated habitats (such as reef flats) also mitigate hazards from waves, storm surges, and tsunamis

${ }^{1}$ Cherokee Nation Technologies.

${ }^{2}$ U.S. Geological Survey. for 7 million U.S. citizens and nearly 200 million coastal residents around the world (Ferrario and others, 2014). Major erosion and degradation of coral reefs and adjacent shallow seafloor habitats are projected in the future due to a variety of anthropogenic activities, placing the functions of these essential ecosystems at risk (Fox and Caldwell, 2006; Madin and Connolly, 2006; Manzello and others, 2008; Burke and others, 2011; Graham and others, 2015; and Yates and others, 2017). In addition to sea level rise, this erosion is accelerating the increase in water depth in these ecosystems (Yates and others, 2017), which further reduces the effectiveness of coral reefs in dissipating wave energy (Ferrario and others, 2014).

By using light detection and ranging (lidar) and multibeam bathymetry surveys together with regional-scale geoprocessing analyses, Yates and others (2017) quantified these effects in coral reef ecosystems within the Florida Reef Tract. However, lidar and multibeam surveys are still susceptible to error and occasionally return values that do not accurately represent "bare-earth bathymetry." Bare-earth bathymetry is defined here as digital elevation data that represent the actual seafloor and exclude false-bottom signals produced by submerged vegetation and man-made structures (Wozencraft and Nayegandhi, 2019). Submerged aquatic vegetation (SAV) and other biota on the seafloor can intercept the transmitted laser pulses to cause incorrect bare-earth readings (Nayegandhi and others, 2009). While post-processing methods exist to filter lidar and multibeam point-cloud data to yield bare-earth data, the geoprocessing analyses that the U.S. Geological Survey (USGS) conducted used digital elevation models (DEMs) published by other agencies. These DEMs were generated using an automated ground-classification algorithm to determine bare-earth point classifications; this algorithm cannot ensure that all points are classified correctly (National Oceanic and Atmospheric Administration, 2017). Among other factors, coral growth (for example, gorgonian coral species), SAV, and algal blooms can cause false returns that are included in final DEM products as inaccurate bare-earth classifications. 
Field reconnaissance (defined here as the collection of photographs and habitat data at study sites) was used to ground truth the results from geoprocessing analyses. As described in this report, the USGS has produced a standard operating procedure (SOP) for the collection of photographic evidence at various areas of interest based on the results of bathymetric elevation change analyses. This SOP was created for a two-member scuba diver team; one diver collects photographic imagery of the site while the other diver collects notes on habitat attributes. Habitat data, photographs, and photograph metadata are timestamped and cataloged to allow for easy access for future analyses.

\section{Methods}

\section{Materials}

An Olympus OM-D E-M10 Mark III camera unit outfitted with an M. Zuiko Digital ED 14-42mm f/3.5-5.6 EZ lens was chosen for this project. This camera system provided 16-megapixel high-resolution photographs with 5-axis image stabilization. This configuration allows for clear imagery to be collected in an easy-to-use format. The camera also has an on-board custom white-balance feature that enables it to compensate for light attenuation at depth. A Nauticam NA-EM10III underwater housing with a Nauticam N85 Power Zoom Macro Port 29 lens port housed the camera unit during fieldwork. The housing has a depth rating of 100 meters (m) and allows full access to all camera functions.

A GEEKOTO 79-inch carbon fiber camera tripod, which was lightweight, easy to transport, and outfitted with a 360-degree ball-head camera mount and quick shoe-plate adapter, provided a stable base on the seafloor. The tripod's 360-degree ball-head swivel camera mount allowed for the accurate and efficient composition of frames and let the viewpoint of the camera be normalized to the horizon without time-consuming adjustments to the tripod legs. The quick shoe-plate adapter allowed the housing unit to be easily attached and detached for mobility in free-swimming scenarios.

Reference pieces - a 3-m steel rod and ruler marked in centimeters $(\mathrm{cm})$ - were used in the field reconnaissance. The 3-m steel rod was made from three lengths of $1-\mathrm{m}$ segments that were threaded and connected using headless threaded bolts. This rod was marked with electrical tape every 0.3 meters. A Hollis TX1 Trimix dive computer was used for in situ depth data collection. Dive slates were used as photograph identifiers and for white balancing of the camera. Sandbags, several lengths of line, and multiple buoys were used to create diving shot lines for site locations at different depths. Field operations were conducted from the USGS research vessel Halimeda, a 25-foot fiberglass hull outfitted with an outboard motor that is used in open-water fieldwork.

\section{Site Determination}

Sites for field reconnaissance were determined using elevation change maps created in the Esri ArcGIS Desktop Advanced version 10.7 mapping and analytics software. Using methods from previously established bathymetric change analyses (Yates and others, 2017), these elevation change maps were created by sampling DEMs from separate time periods and comparing elevation values. Areas that had significant elevation changes relative to the mean elevation change of the full geographic survey were labeled as "hot spots" (fig. 1) and these areas were chosen for ground truthing through field reconnaissance.

\section{Photographic Operations}

Following site determination, the field team used a Global Positioning System (GPS) receiver to mark the site with a sandbag, which was lowered from the vessel and released adjacent to the GPS receiver when the boat operator vocally confirmed the correct positioning of the vessel. Approximately $20 \mathrm{~m}$ of rope and a buoy were attached to the sandbag. The following procedures can be completed in approximately 10 minutes, which allows for the rapid assessment of site characteristics and the ability to document many sites in a single day.

\section{Site and Reference Preparation}

After the divers entered the water, the 3-m reference rod was positioned so that one end was touching the center of the sandbag and the other was oriented exactly due north by utilizing a dive compass. Extra care was taken to minimize the disturbance of the surrounding substrate. Once at depth, the camera was normalized to account for light attenuation by using the on-board custom white balance functionality; a blank dive slate served as a reference white surface to provide a closer representation of true ground color. After completing these steps, each site was documented in a specific order:

1. the dive slate with site information;

2. a nadir viewpoint parallel to the reef surface;

3. north $(\mathrm{N})$, east $(\mathrm{E})$, south $(\mathrm{S})$, and west (W) viewpoints perpendicular to the reef surface;

4. a macro shot of the seafloor sediment alongside the reference ruler; and

5. any additional points of interest from the surrounding area. 


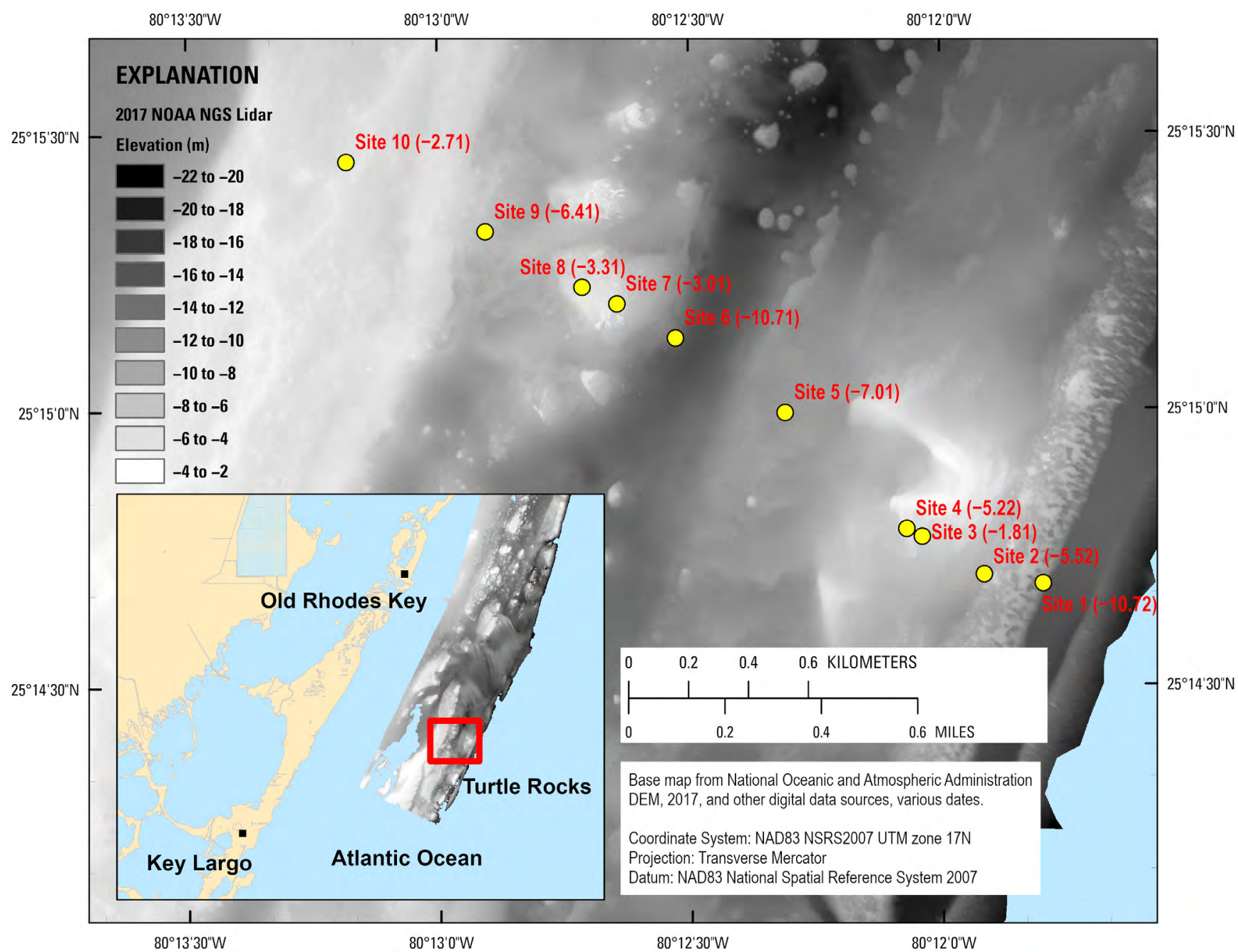

Figure 1. Map showing the ten "hot spot" sites chosen for Turtle Rocks, Florida Keys, Florida; the location is shown in the inset map. Except for figure 7, all of the photographs in this report are from site 7. Yellow circles represent "hot spots" that were identified from elevation change analyses (Yates and others, 2017; Yates and others, 2019); the corresponding values (in parentheses next to the site number) are the differences in elevation from 2002 and 2017 lidar data. Underlying bathymetry is a digital elevation model (DEM) that was created from the 2017 National Oceanic and Atmospheric Administration, National Geodetic Survey (NOAA NGS) Topobathy Lidar: Florida Keys Outer Reef Block 04 (National Oceanic and Atmospheric Administration, 2017). Terms: lidar, light detection and ranging; NAD83, North American Datum of 1983; NSRS2007, National Spatial Reference System 2007; UTM, Universal Transverse Mercator.

The first photograph of the dive slate indicates the location and site number and serves as an initial reference shot for all photographs taken at the site (fig. 2). When multiple sites are surveyed in succession, each reference shot also serves to separate photographs taken at different sites, as the photographs are consecutively recorded on the camera's secure digital (SD) card.

\section{Nadir Imagery}

The nadir shot was taken by using an extended camera tripod as a rough reference to capture a photograph at approximately $2 \mathrm{~m}$ above and parallel to the seafloor. The orientation of the nadir shot was determined by placing the sandbag in the center of the frame; the reference rod was placed with one end touching the sandbag and the other extending northwards and out of the frame (fig. 3). 


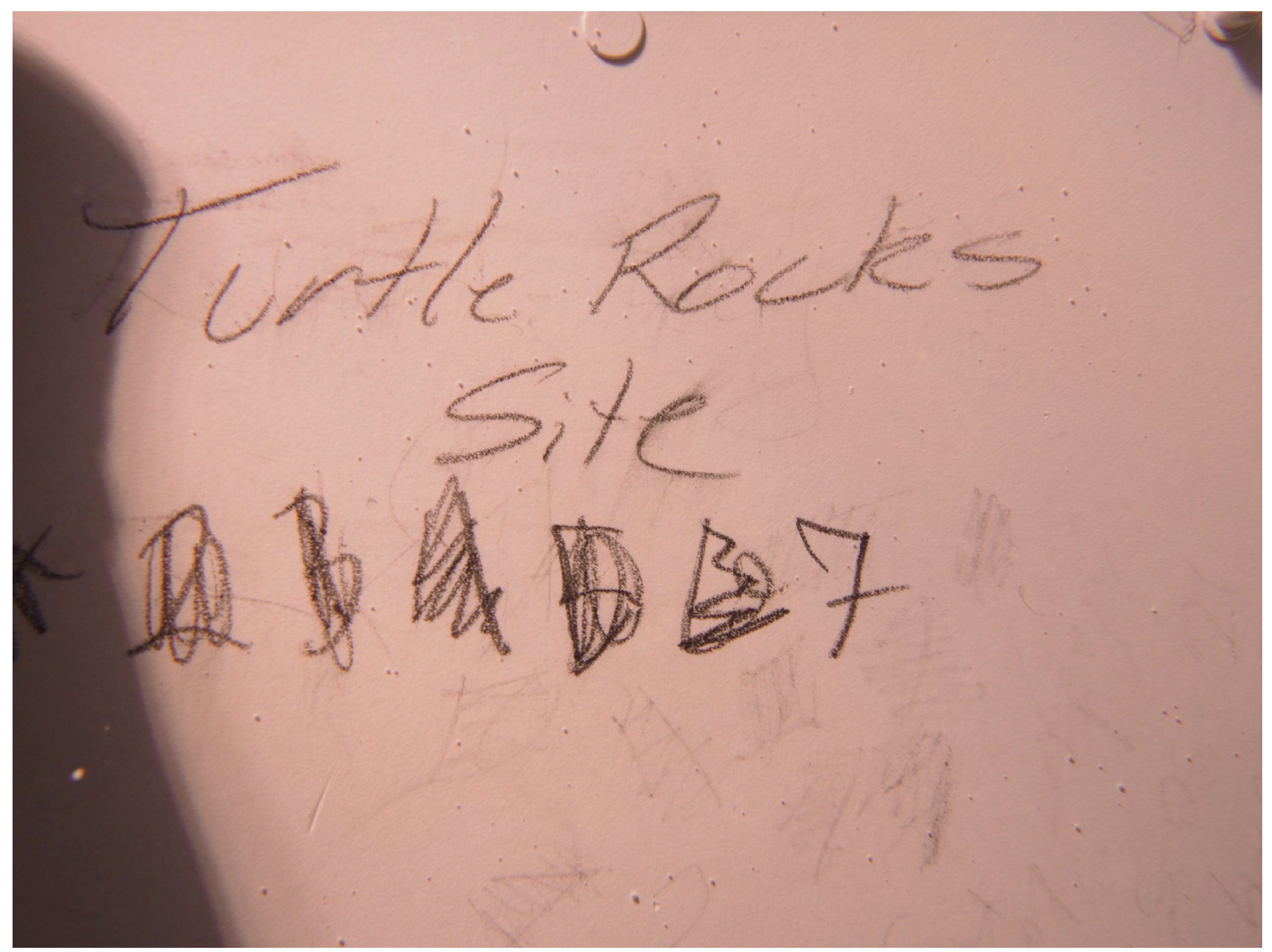

Figure 2. Underwater photograph of the dive slate (showing "Turtle Rock site 7") which was used to demarcate the beginning of the series of photographs taken at Turtle Rocks site 7 on the camera's chronologically ordered secure digital (SD) card. Photograph by Zachery Fehr.

\section{Cardinal Direction Imagery}

Following the nadir shot, the tripod was set to a height of $2 \mathrm{~m}$ directly above the center of the sandbag (fig. 4). Using the markings on the tripod's 360-degree swivel mount, the camera and frame were oriented north with the swivel mount set to 0 degrees. With the camera's live view screen, the top third of the frame showed open water while the bottom two thirds of the frame included the bathymetry and the reference rod. The reference rod was positioned in the center of the frame extending outwards.

Once all equipment was positioned, a compass reading was taken to confirm that the orientation of the camera was accurate. Each cardinal direction was photographed both with and without a dive slate (fig. 5) that was marked with the letters "N," "E," "S," and "W" (to indicate viewpoints to the north, east, south, and west, respectively). The photographs of the dive slates served as reference images to orient each of the photographs during post-fieldwork sorting. The northerly viewpoint was photographed first; the photograph of the dive slate marked " $\mathrm{N}$ " served as the reference for the remaining cardinal-direction orientated images. After a direction was fully documented, the swivel mount was used to rotate the camera 90-degrees clockwise and the reference rod was repositioned to the center of the new frame. The next cardinal-direction view was photographed using the same process; this procedure was repeated until each cardinal direction was photographed. Multiple photographs of each frame were taken to compensate for potential distortion due to vibration or focusing issues. 


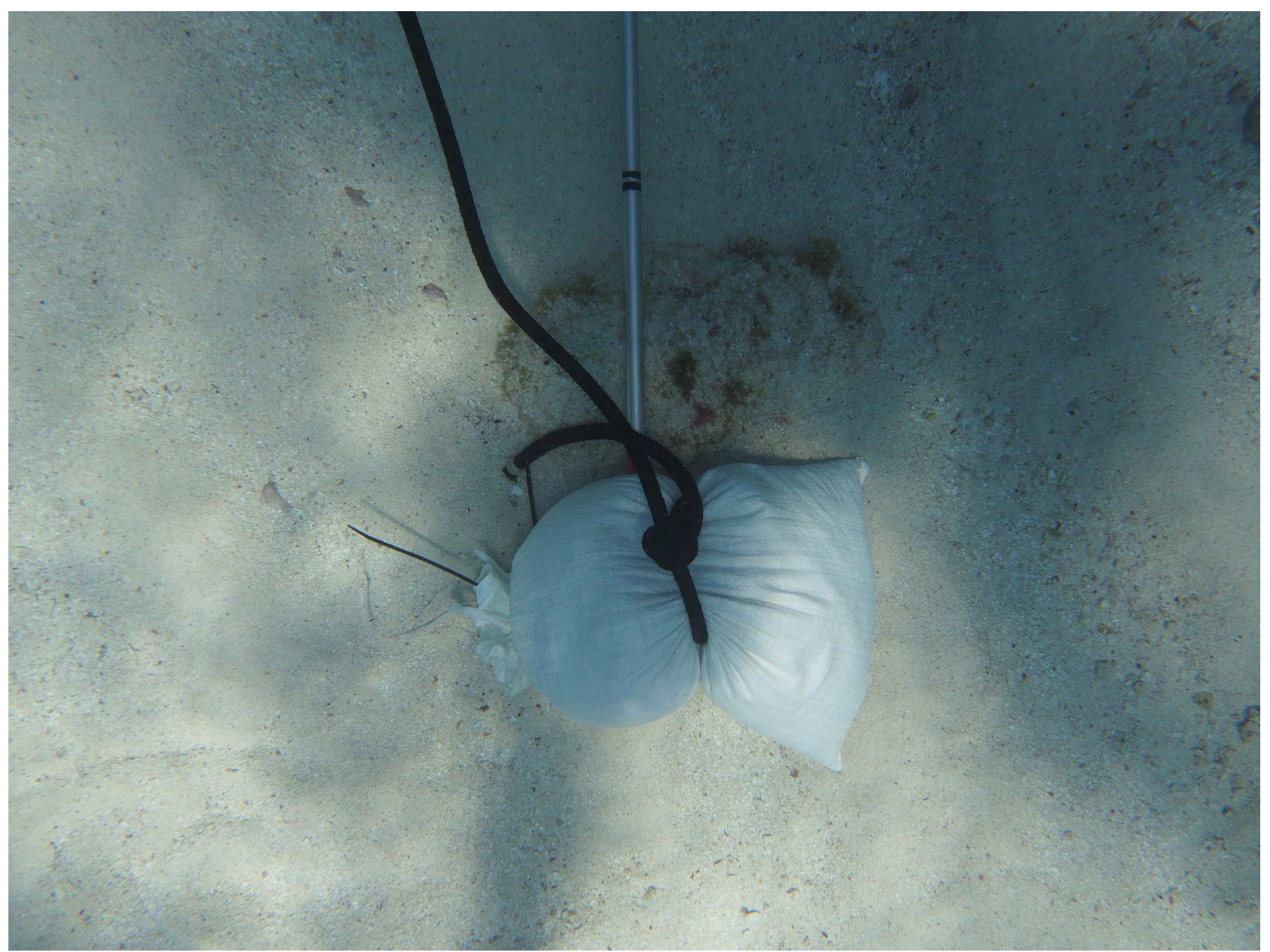

Figure 3. Photograph of an example nadir shot at Turtle Rocks site 7. The reference rod is positioned northwards (out of frame) with one end touching the sandbag. Photograph by Zachery Fehr.

\section{Supplemental Imagery}

When all of the cardinal directions were documented, the camera was removed from the tripod and macro shots were taken of the sediment alongside a reference ruler at the closest proximity that allowed for focus and framing of the reference ruler (fig. 6). Any erosion or accretion features in the area were also photographed alongside a reference ruler. For example, the partial burial of a gorgonian coral species was observed at Crocker Reef site 3 (fig. 7A). Sediment was gently swept away from the base and down to the holdfast of one or more of these gorgonians (fig. $7 \mathrm{~B}$ ) to estimate the amount of sediment accretion that had occurred. 


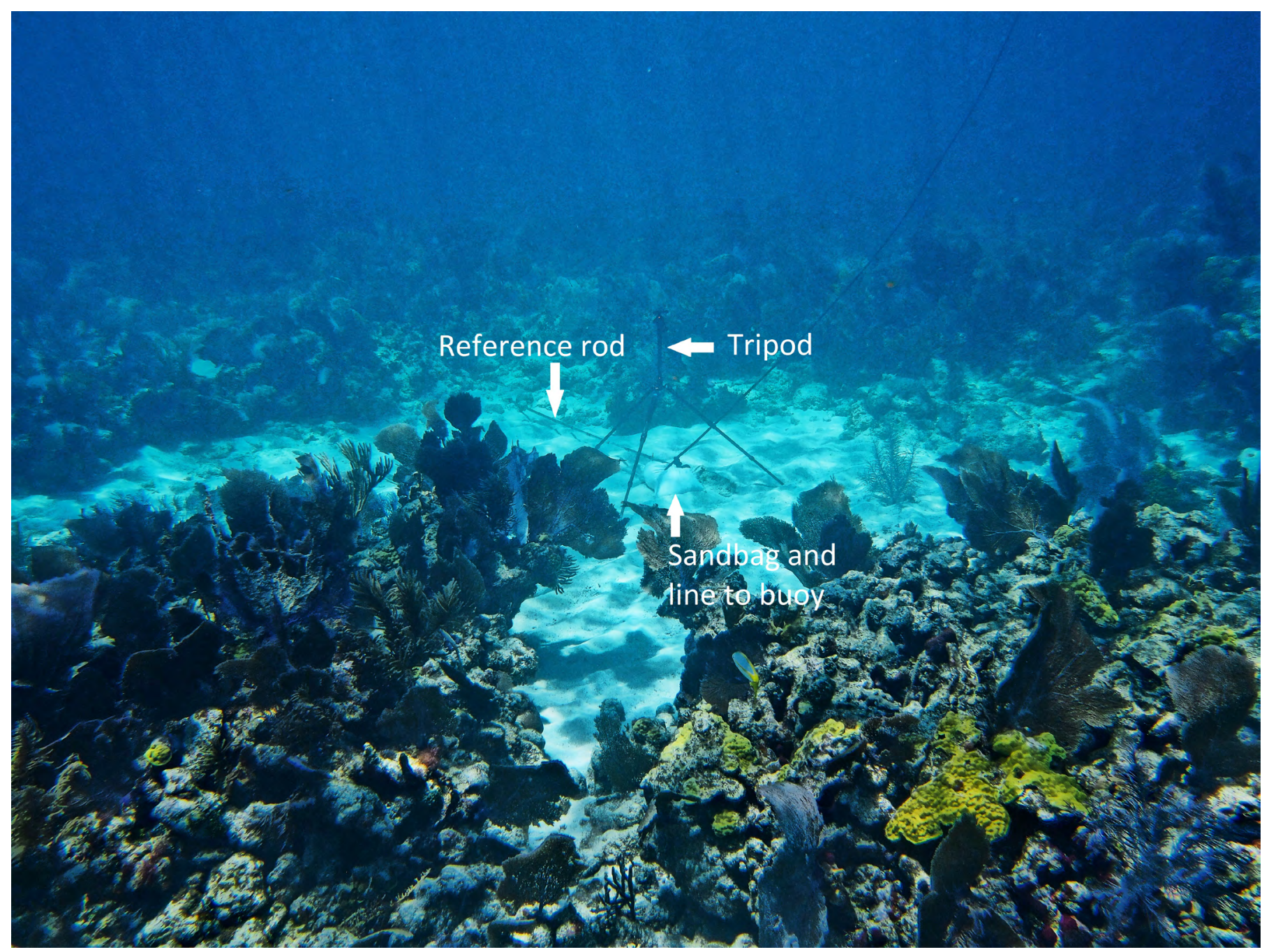

Figure 4. Photograph of the tripod and reference rod setup at Turtle Rocks site 7. Tripod height is approximately 2 meters. The sandbag and line to the buoy are also shown. Photograph by Zachery Fehr. 

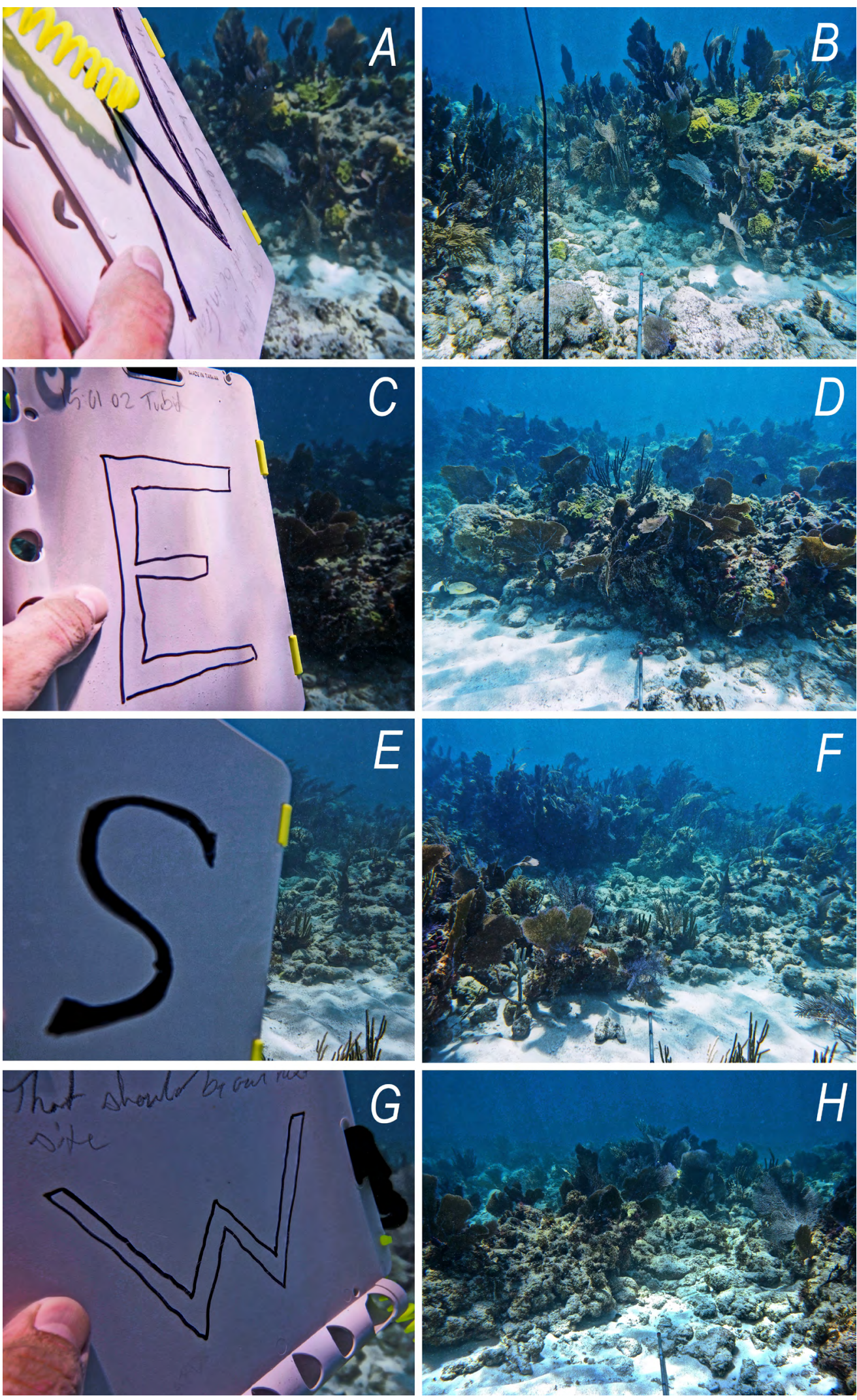

Figure 5. Photographs showing cardinal direction viewpoints at Turtle Rocks site $7(A, C, E, G)$ with the reference dive slate and $(B, D, F, H)$ without the reference dive slate. Paired directional photographs show $(A, B)$ the northerly view; $(C, D)$ the easterly view; $(E, F)$ the southerly view; and $(G, H)$ the westerly view. The reference rod is 3 meters long and is visible at the base of each photograph. Photographs by Zachery Fehr. 


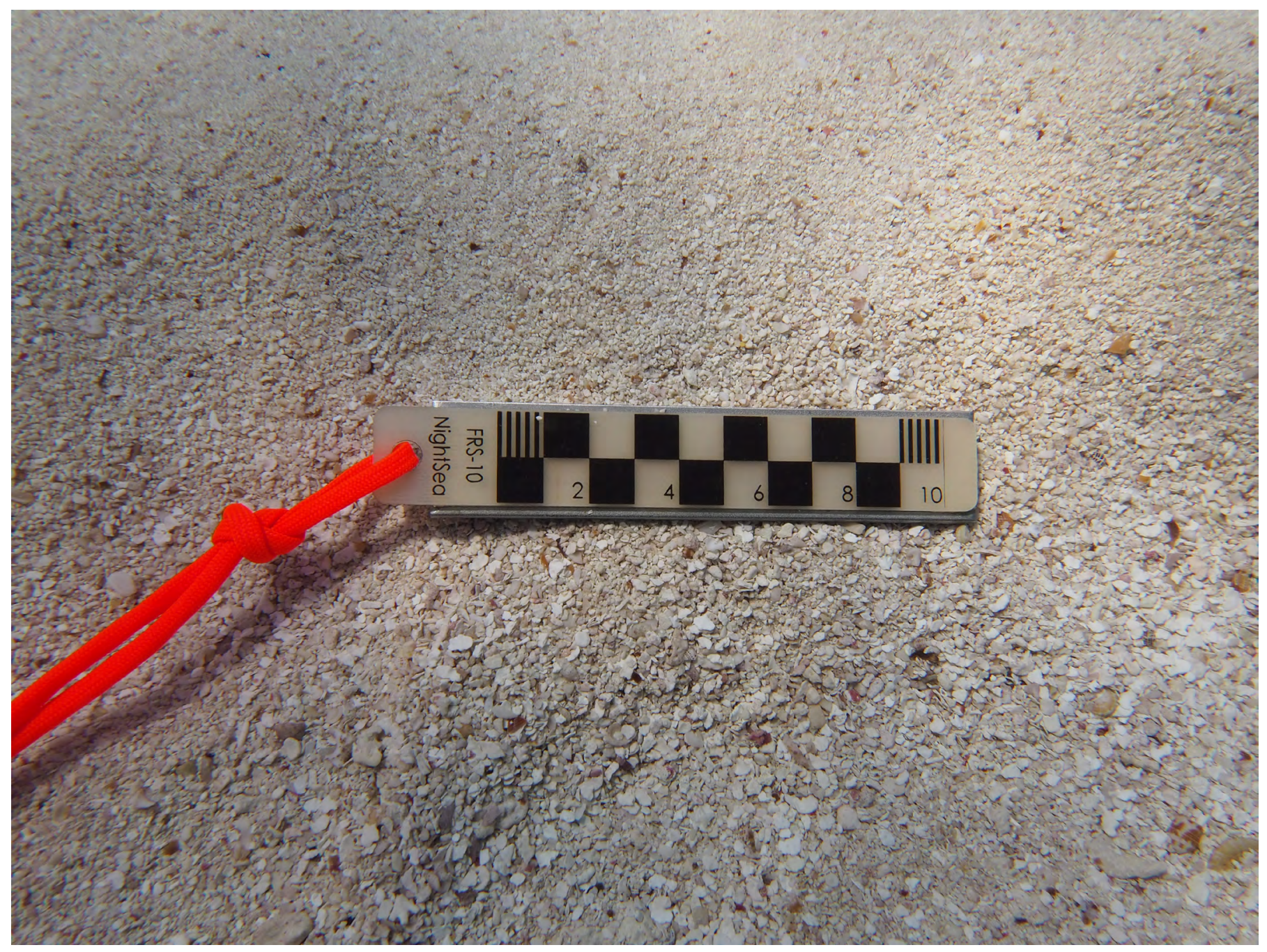

Figure 6. Photograph (a macro shot) of seafloor sediment alongside a reference ruler at Turtle Rocks site 7. The reference ruler units are in centimeters. Photograph by Zachery Fehr. 

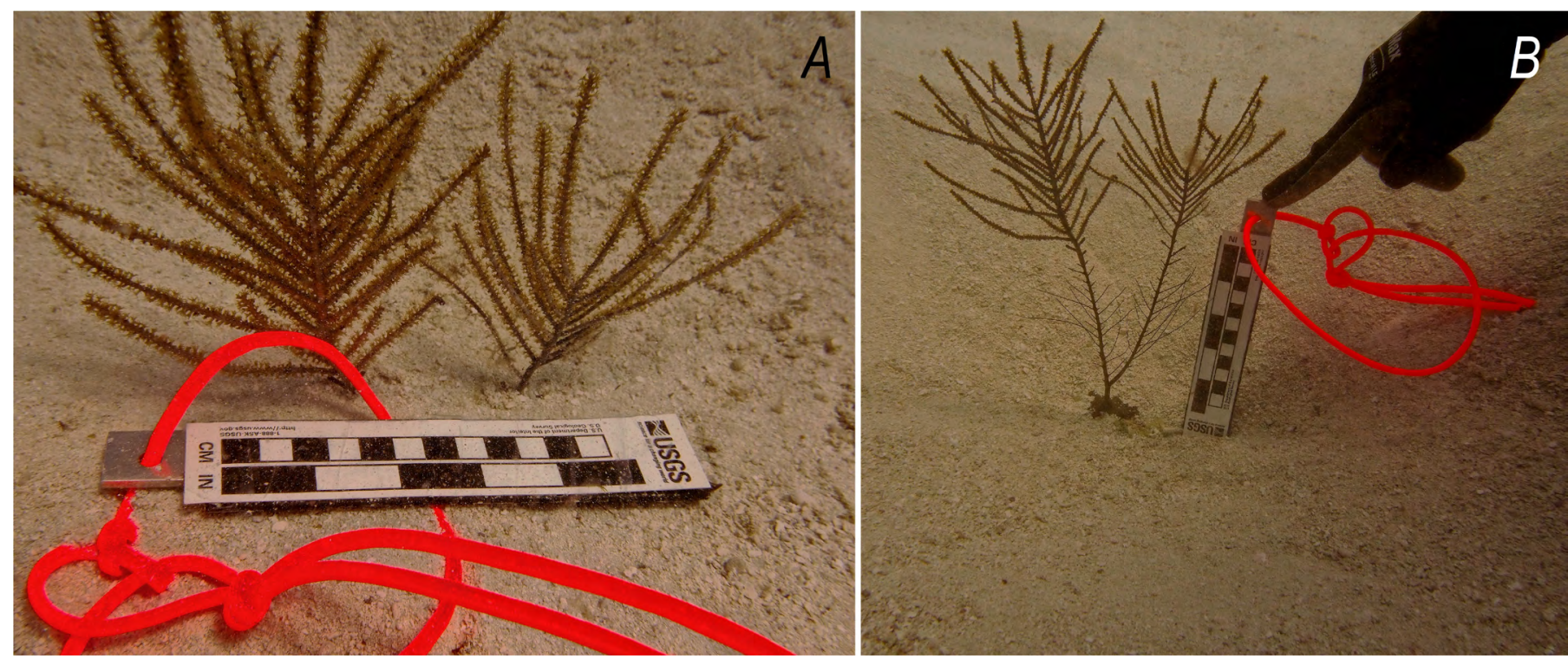

Figure 7. Photograph showing sediment accretion around a gorgonian coral species found at Crocker Reef site $3(A)$ before sediment removal from the holdfast and $(B)$ after sediment removal from the holdfast. Photographs by Zachery Fehr.

\section{Habitat Sheet Data Collection}

One diver operated the camera while the other diver recorded habitat data on a waterproof printout of an "Ecosystem Processes Impacting Coastal Change (EPIC) Recon Dive Habitat Sheet" (fig. 8). This habitat sheet is a modified version of the Rapid Habitat Assessment Sheet from the Coral Reef Monitoring Protocol Narrative (Version 2.0) that was developed by the National Park Service for marine benthic composition assessments (Miller and others, 2017). Several habitat characteristics were recorded, including the date and time of the dive and the geographic coordinates of the site. Water depth, in feet, was measured by placing a dive computer on the seafloor and recording the depth reading. The minimum and maximum depths within a $2-\mathrm{m}$ radius of the sandbag were measured. Visual estimation was used to categorize the broad-scale habitat rugosity as low (meaning the tallest hard structure was less than $0.5 \mathrm{~m}$ ), medium (meaning the tallest hard structure was from 0.5 to $1.5 \mathrm{~m}$ ), or high (meaning the tallest hard structure was greater than $1.5 \mathrm{~m}$ ).

The habitat structure type and percent coverage of substratum were determined through visual analysis. Habitat structure types were derived from the Unified Florida Reef Tract Map provided by the Florida Fish and Wildlife Conservation Commission. This regional map shows benthic habitats along the Florida Reef Tract from Martin County, Fla., to the Dry Tortugas Islands (https://ocean.floridamarine.org/ IntegratedReefMap/UnifiedReefTract.htm). The substratum was characterized by estimating the percent coverage of abiotic (hardbottom, rubble, sand, and silt/mud) and biotic (live coral, gorgonians, sponges, macroalgae, seagrass, and bare/turf/uncolonized) substratum within a 2-m radius of the sandbag. Transition zones and adjacent habitats occurring within a few meters of the site were also noted on the habitat sheet, as they could aid in discerning any variability in geoprocessing results. Finally, any relevant information that did not fall within the previous fields was recorded in the "Photo numbers \& Notes" section of the habitat sheet (fig. 8).

\section{Photograph Metadata}

Typical field reconnaissance excursions may result in thousands of photographs, depending on the number of sites visited. The methods used in this report resulted in approximately 50 photographs per site, with the number depending on site characteristics. A catalog of all collected photographs, including metadata, was created. The photographs were downloaded to an on-site laptop computer at the end of each day during the research trip and were transferred to the USGS data server at the St. Petersburg Coastal and Marine Science Center upon returning to the office. 


\section{EPIC Recon Dive Habitat Sheet}

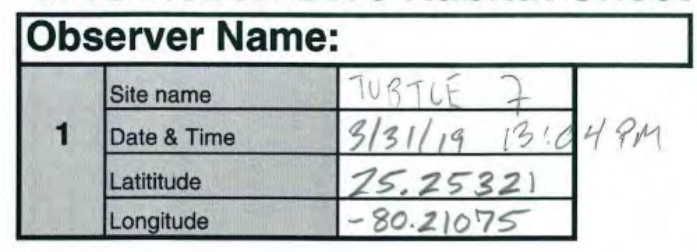

\begin{tabular}{|l|l|l|}
\hline \multirow{2}{*}{2} & \multicolumn{3}{|l|}{ Depth (feet - use depth gauge) } \\
\cline { 2 - 3 } & Min* & Max * \\
\cline { 2 - 3 } & & 18 \\
\hline
\end{tabular}

${ }^{*}$ Max $=$ depth to lowest point of sea floor

${ }^{*}$ Min $=$ depth to highest point of sea floor

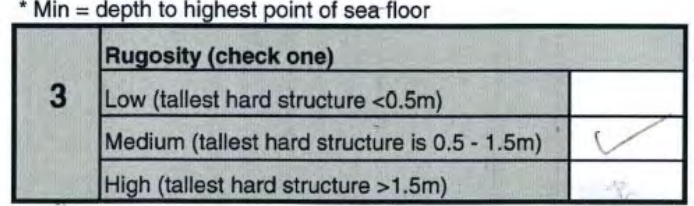

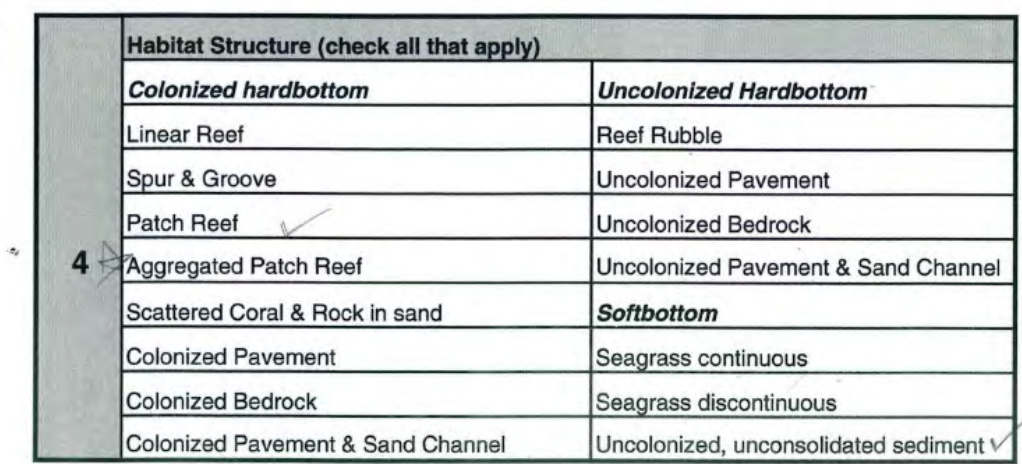

\section{FAN:}

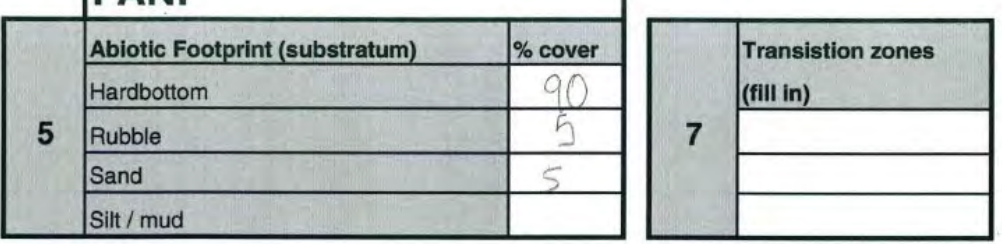

6

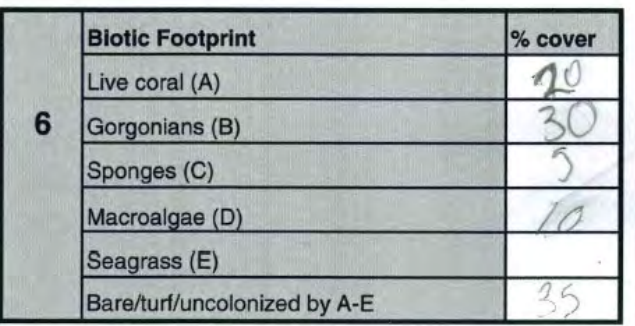

Photo numbers \& Notes

Figure 8. Digital image of the completed "Ecosystem Processes Impacting Coastal Change (EPIC) Recon Dive Habitat Sheet" for Turtle Rocks site 7.

Photographs were saved in the Olympus Raw Format (ORF) and Joint Photographic Experts Group (JPG) formats. The ORF format is Olympus' proprietary version of a raw format and can be read by photographic editing software as a standard raw file. Raw images are minimally processed files that are taken by a camera's sensor. This format allows the image to be processed and edited in a non-destructive manner because the original raw file is never changed. The camera processes each raw file to create a JPG image based on the camera settings at the time each photograph is taken. This in-camera processing results in compression and a loss of image data. Any edits made to the JPG image further compress it, which results in an additional loss of image data and lower quality images. However, the use of raw files allows images to be manipulated from the least-processed data available; they can be converted into a JPG or other image format using more powerful image editing software in order to create the highest possible quality images for publication.
File names were generated by the camera and followed a "M/DD/\#\#\#\#" naming convention. For example, P3311661. JPG (fig. 5A) was taken on March 31st and was the 1,661st photograph to be stored in the SD card folder. The "P" indicates that the image uses standard Red Green Blue (sRGB) color space, which is the default for contemporary digital cameras and allows the images to be processed by operating systems, displayed on monitors, and read by printers. The metadata catalog was created in Microsoft Excel 2016. Each row in the spreadsheet represents a single photograph and its metadata (table 1). The entries were organized based on location, site number, and the frame photographing order. The remainder of the metadata were sourced from previous bathymetric analyses (Yates and others, 2017, 2019), from the photograph's exchangeable image file format (EXIF) data, or were collected in situ during field reconnaissance. 


\section{Discussion}

Seafloor characterizations performed using remotely sensed data (such as bathymetric lidar) or towed-in-water sensor data benefit from fieldwork to check the accuracy of the data. As described in this report, a simple, efficient, and rapid seafloor assessment SOP was developed by the USGS to assist with ground truthing of seafloor bathymetry data and elevation change analyses in shallow coral reef ecosystems in the Florida Reef Tract. However, these methods can be applied to other geospatial or habitat assessments in a variety of coastal environmental settings.

This assessment can be performed by a team of two scuba divers and includes a method for consistent, repeatable documentation of seafloor characteristics, appropriate metadata collection, and photograph cataloging procedures. Use of this SOP for ground truthing should be performed coincident with, or as soon as possible after, sensor data collection. The ability to quickly supplement sensor data with photographic evidence allows for a more detailed view of the changes that the seafloor undergoes during high-energy storm events. The use of this process allows for consistency in photographing and documenting a location on the seafloor. As a result, newer images can be superimposed over older images to assist in longitudinal studies of the location. Photograph catalogs developed with this methodology, along with the metadata files, are currently maintained at the St. Petersburg Coastal and Marine Science Center for ease of reference and accessibility for research.

Table 1. List of fields associated with image P3311661.JPG (fig. $5 A$ ) in the photograph metadata.

[DEM, digital elevation model; EST, Eastern Standard Time; f, foot; FAN, field activity number; ID, identification; JPG, Joint Photographic Experts Group; m, meter; n/a, not applicable; ORF, Olympus Raw Format; \%, percent]

\begin{tabular}{|c|c|c|}
\hline Metadata field & Explanation & Example entry \\
\hline FAN & Field activity number, denotes associated project & 2019-313-FA \\
\hline Location & Geographic description of the study site & Turtle Rocks \\
\hline Location description & Seafloor feature description of the location & Top of patch reef \\
\hline Date & Date in month/day/year & $3 / 31 / 2019$ \\
\hline Time (EST) & Time in 12-hour clock format & 1:12:00 PM \\
\hline Photo orientation & Description of photograph frame & North \\
\hline Photo ID & $\begin{array}{l}\text { Camera designated ID number for camera-generated JPG file, hyperlinked to } \\
\text { photograph's storage location }\end{array}$ & P3311661.JPG \\
\hline Min depth (f) & Minimum depth at site in feet & 10 \\
\hline Min depth (m) & Minimum depth at site in meters & 3.0 \\
\hline Max depth (f) & Maximum depth at site in feet & 18 \\
\hline Max depth (m) & Maximum depth at site in meters & 5.5 \\
\hline Diff_m (2016-2017) & $\begin{array}{l}\text { Difference in elevation between } 2016 \text { DEM and } 2017 \text { DEM at site } \\
\text { coordinates in meters }\end{array}$ & $\mathrm{n} / \mathrm{a}$ \\
\hline Diff_m $(1934 / 1935-2002)$ & $\begin{array}{l}\text { Difference in elevation between 1934/1935 historical data and } 2002 \text { DEM at } \\
\text { site coordinates in meters }\end{array}$ & -1.2 \\
\hline Site character & Accretion or erosion based on Diff_m & Erosion \\
\hline
\end{tabular}




\section{Underwater Photographic Reconnaissance and Habitat Data Collection in the Florida Keys}

Table 1. List of fields associated with image P3311661.JPG (fig. 5A) in the photograph metadata.—Continued

[DEM, digital elevation model; EST, Eastern Standard Time; f, foot; FAN, field activity number; ID, identification; JPG, Joint Photographic Experts Group; m, meter; n/a, not applicable; ORF, Olympus Raw Format; \%, percent]

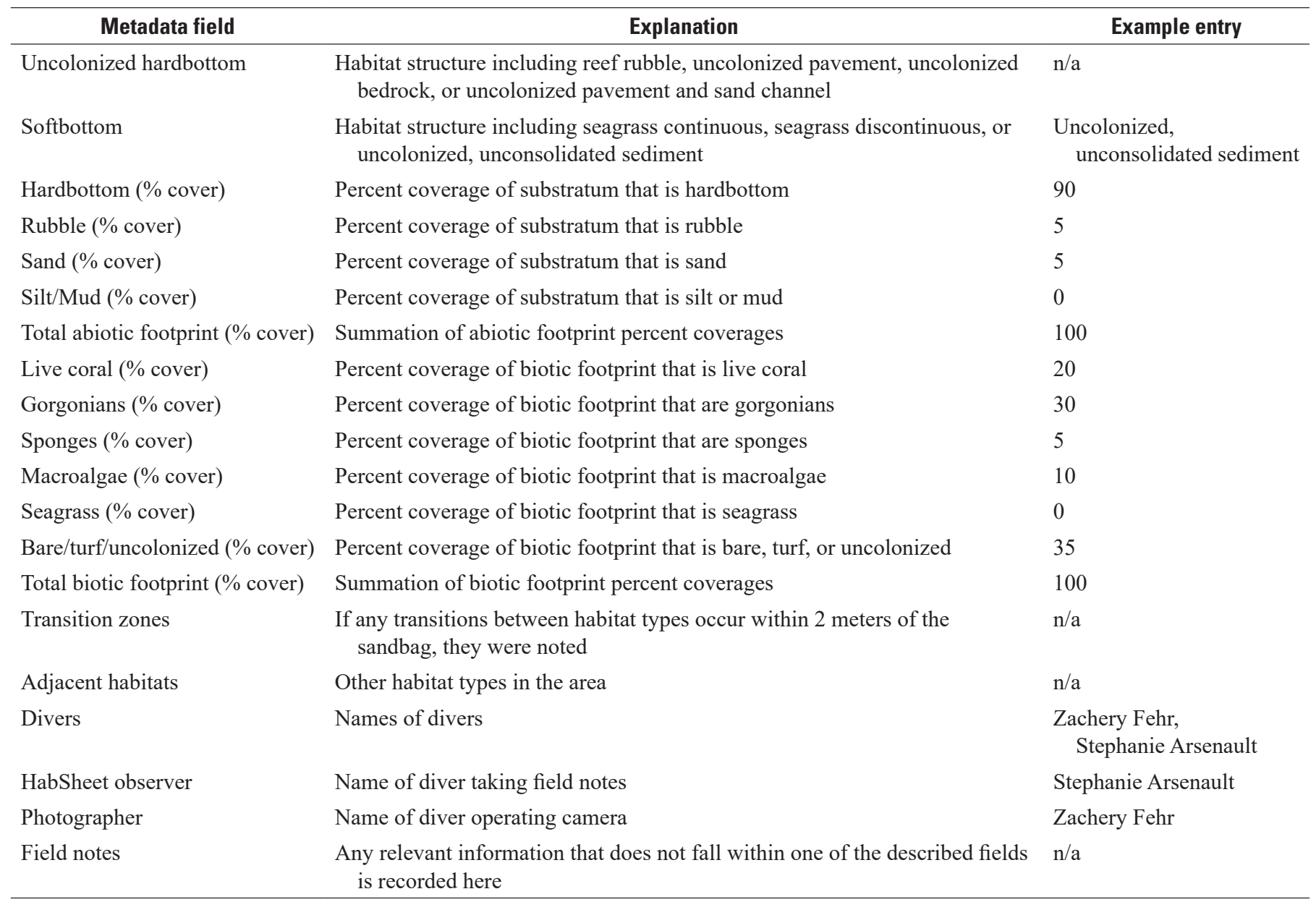




\section{References Cited}

Burke, L., Reytar, K., Spalding, M., and Perry, A., 2011, Reefs at risk revisited: Washington, D.C., World Resources Institute, 114 p., accessed December 9, 2019, at https://www.wri.org/publication/reefs-risk-revisited.

Ferrario, F., Beck, M.W., Storlazzi, C.D., Micheli, F., Shepard, C.C., and Airoldi, L., 2014, The effectiveness of coral reefs for coastal hazard risk reduction and adaption: Nature Communications, v. 5, no. 1 , article 3794, 9 p., accessed November 5, 2019, at https://doi.org/10.1038/ncomms4794.

Fox, H.E., and Caldwell, R.L., 2006, Recovery from blast fishing on coral reefs-A tale of two scales: Ecological Applications, v. 16, no. 5, p. 1631-1635, accessed December 9, 2019, at, https://doi.org/10.1890/10510761(2006)016[1631:RFBFOC]2.0.CO;2.

Graham, N.A.J., Jennings, S., MacNeil, M.A., Mouillot, D., and Wilson, S.K., 2015, Predicting climate-driven regime shifts versus rebound potential in coral reefs: Nature, v. 518 , no. 7537 , p. $94-97$, accessed December 9, 2019, at https://doi.org/10.1038/nature14140.

Madin, J.S., and Connolly, S.R., 2006, Ecological consequences of major hydrodynamic disturbances on coral reefs: Nature, v. 444, no. 7118, p. 477-480, accessed December 9, 2019, at https://doi.org/10.1038/nature05328.

Manzello, D.P., Kleypas, J.A., Budd, D.A., Eakin, C.M., Glynn, P.W., and Langdon, C., 2008, Poorly cemented coral reefs of the eastern tropical Pacific-Possible insights into reef development in a high- $\mathrm{CO}_{2}$ world: Proceedings of the National Academy of Sciences of the United States of America, v. 105, no. 30, p. 10450-10455, accessed December 9, 2019, at https://doi.org/10.1073/pnas.0712167105.
Miller, J., Rogers, C.S., Feeley, M.W., Atkinson, A.J., Davis, A.D., Patterson, M.E., Waara, R.J., Witcher, B.D., Patterson, J.M., and Muller, E.M., 2017, Coral reef monitoring-Protocol narrative-Version 2.0: National Park Service Natural Resource Report, NPS/ SFCN/NRR - 2017/1464, 86 p. [Also available at https://irma.nps.gov/DataStore/Reference/Profile/2240837.]

National Oceanic and Atmospheric Administration, 2017, 2017 NOAA NGS topobathy lidar-Florida Keys outer reef block 04: National Oceanic and Atmospheric Administration dataset, accessed March 19, 2020, at https://www.fisheries.noaa.gov/inport/item/51529.

Nayegandhi, A., Brock, J.C., and Wright, C.W., 2009, Small-footprint, waveform-resolving lidar estimation of submerged and sub-canopy topography in coastal environments: International Journal of Remote Sensing, v. 30 , no. 4 , p. $861-878$, accessed November 5, 2019, at https://doi.org/10.1080/01431160802395227.

Wozencraft, J., and Nayegandhi, A., 2019, Airborne lidar bathymetry, chap. 10 of Maune, D.F., and Nayegandhi, A., eds., Digital elevation model technologies and applications-The DEM users manual (3d ed.): Bethesda, Md., American Society for Photogrammetry and Remote Sensing, $285 \mathrm{p}$.

Yates, K.K., Zawada, D.G., and Arsenault, S.R., 2019, Seafloor elevation change from 2016 to 2017 at Looe Key, Florida Keys-Impacts from Hurricane Irma: U.S. Geological Survey data release, accessed December 9, 2019, at https://doi.org/10.5066/P937LNZF.

Yates, K.K., Zawada, D.G., Smiley, N.A., and Tiling-Range, G., 2017, Divergence of seafloor elevation and sea level rise in coral reef ecosystems: Biogeosciences, v. 14, no. 6, p. 1739-1772, accessed November 5, 2019, at https://doi.org/10.5194/bg-14-1739-2017. 

For more information concerning the research in this report, contact Director, St. Petersburg Coastal and Marine Science Center U.S. Geological Survey 600 4th Street South

St. Petersburg, FL 33701

Publishing support provided by the U.S. Geological Survey Science Publishing Network, Reston and Sacramento Publishing Service Centers 
